\title{
A study of efficacy of oral iron and intravenous iron sucrose in the treatment of moderate anemia in pregnancy
}

\author{
Saloni M. Prajapati, Meha K. Patel* \\ Department of Obstetrics and Gynecology, GMERS Medical College, Gotri, Vadodara, Gujarat, India \\ Received: 25 April 2019 \\ Accepted: 06 May 2019 \\ *Correspondence: \\ Dr. Meha K. Patel, \\ E-mail: meha.patel151@gmail.com \\ Copyright: (c) the author(s), publisher and licensee Medip Academy. This is an open-access article distributed under \\ the terms of the Creative Commons Attribution Non-Commercial License, which permits unrestricted non-commercial \\ use, distribution, and reproduction in any medium, provided the original work is properly cited.
}

\begin{abstract}
Background: Iron deficiency anaemia in pregnancy is a common medical problem throughout India with the burden of disease impacting on both mother and the newborn. It is also responsible for increased incidence of premature births, low birth weight babies and high perinatal mortality. Intravenous iron sucrose and oral iron therapy are the primary therapeutic modalities for management of iron deficiency anaemia during pregnancy, but its efficacy during pregnancy is still a matter of argument among healthcare personnel. Therefore the objective of this study is to compare the effect of oral iron and intravenous iron sucrose on hemoglobin and other blood indices among pregnant females with iron deficiency anemia.

Methods: Randomized clinical trial was conducted among 400 females between 20 to 34 weeks gestation with iron deficiency anemia who were managed either with oral ferrous sulphate or intravenous iron sucrose therapy. $Z$ test was used for statistical analysis for significance with $95 \%$ confidence interval. The hemoglobin and blood indices levels before and after initiating treatment in both groups were compared.

Results: Intravenous and oral; both the treatments were associated with increment in hemoglobin but this rise was significantly more in the intravenous group than in oral. Comparing participants with low pretreatment hemoglobin among both groups, participants in the intravenous group were better benefited than oral due to respective treatment. Conclusions: Intravenous iron therapy is much effective in correcting iron deficiency anemia in pregnancy than oral iron therapy. It restores iron stores more promptly. Also intravenous iron is better tolerated compared to oral iron.
\end{abstract}

Keywords: Anemia, Iron deficiency, Iron sucrose

\section{INTRODUCTION}

Anaemia is defined as haemoglobin level in the blood is below the lower extreme of the normal range for the age and sex of the individual. Anaemia is a widespread public health problem with major consequences for human health as well as social and economic developmen. ${ }^{1}$ According to WHO, in developing countries the prevalence of anaemia among pregnant women averages $56 \%$, ranging between 35 to $100 \%$ among different regions of the world. ${ }^{2}$ Various studies from different regions of the country (India) have reported the prevalence of anaemia to be between 33 and $100 \%{ }^{3,4}$ In India up to $88 \%$ of pregnant women are affected with anaemia. ${ }^{5}$ Among these, $50 \%$ of anaemia in pregnancy is due to iron deficiency. ${ }^{6}$ Iron deficiency anemia in our country is due to inadequate iron intake in the habitual diets combined with the poor bioavailability of dietary iron.

Anaemia is the second most common cause of maternal deaths, accounting for $20 \%$ of all maternal deaths directly 
and indirectly to another $20 \%$ of maternal deaths and $9 \%$ of perinatal mortality. ${ }^{7-9}$ There is $2-3$ fold increase in perinatal mortality when Haemoglobin is less than $8 \mathrm{gm} / \mathrm{dl}$ and $8-10$ fold increase when maternal haemoglobin falls below $5 \mathrm{gm} / \mathrm{dl} .{ }^{10}$ Anaemia results in increased number of preterm births, preeclampsia, LBW, IUGR, PPH, failure of lactation and increased risk of infections in post partum period. ${ }^{11} \mathrm{~A}$ consistent finding in different countries is that severe, chronic iron deficiency in infancy identifies children with poorer cognitive function and lower scores in school achievement tests, suggesting that irreversible abnormalities result from a deficiency at a critical period of growth and differentiation of the brain. ${ }^{12}$

Haemoglobin level at or below $9 \mathrm{gm} / \mathrm{dl}$ requires detailed investigations and appropriate treatment. So it is that segment of moderate iron deficiency anemia which is required to be treated vigorously in second trimester itself. Hence prevention and correction of anaemia during pregnancy is vital for safe motherhood. Oral iron has been the first line of treatment for treating anaemia during pregnancy, but a considerable number of patients did not improve because of reasons like intolerance to oral iron, inadequate absorption, and side effects leading to non compliance due to which treatment becomes inadequate and in such conditions parenteral iron therapy is preferred. According to World Health Organisation (WHO), oral iron preparations have been proved to be inadequate to reduce frequency of Iron deficiency anaemia. Many antenatal women have been observed to be iron deficient despite routine use of iron prophylaxis adopted by health centres in developing countries. The WHO technical group working on the prevention and treatment of anaemia has documented that parenteral iron therapy has produced a rapid and complete correction of iron deficiency anaemia than oral iron therapy. ${ }^{13}$ Among all the parenteral iron preparations available, Iron sucrose appears to be efficient because of its good safety record and it overcomes the problems of absorption and compliance compared to iron dextran, iron gluconate and also blood transfusion. ${ }^{14,15}$

Objectives of this study was to study efficacy and safety of intravenous iron sucrose and oral ferrous sulphate in correcting hemoglobin in pregnant women, and to compare effectiveness of intravenous iron sucrose over oral iron preparation of iron in correcting Iron deficiency anemia of pregnancy.

\section{METHODS}

All the patients attending Antenatal care OPD between September 2018 and February 2019 were screened retrospectively with the help of inclusion and exclusion criteria as follows.

\section{Inclusion criteria}

- $\quad$ Age 20 to 35 years
- Singleton pregnancy completing 20 weeks of gestation up to 32 weeks

- Anemia as per definition of World Health Organization, hemoglobin between 7 to $9 \mathrm{~g} / \mathrm{dL}$ or hematocrit of $<30 \%$

- Patients who received three to five doses of intravenous iron sucrose $200 \mathrm{mg}$ each on alternate day were included in the intravenous iron therapy group

- Patients who received tablet ferrous sulphate with $100 \mathrm{mg}$ elemental iron single tablet twice daily for 6 weeks were included in the oral iron therapy group.

\section{Exclusion criteria}

- Underlying disease such as hypertension, gestational diabetes mellitus, heart disease, peptic ulcer, etc.

- History of antepartum hemorrhage likely to recur, for example placenta previa

- Hemoglobinopathy like sickle cell trait/disease, thalassemia disease detected by hemoglobin high performance liquid chromatography (Hb HPLC), for example $\mathrm{B}$ thalassemia major

- History of bleeding tendency or blood transfusions.

Clotting time, and random blood sugar (RBS) and ultrasonography (USG) to rule out exclusion criteria. Thorough history was elicited and clinical examination was done. 100 Antenatal women were assigned into the study group. An informed consent was taken from each woman before the study. Study group received iron sucrose intravenously; the dose was calculated using the following formula, $2.4 \mathrm{x} \mathrm{Hb}$ deficit (in $\mathrm{gm} \%$ ) $\mathrm{x}$ prepregnancy body weight (in kgs) +500mg. ${ }^{16,17} 500 \mathrm{mg}$ was to replenish iron reserves. Thus obtained dose is given in divided doses, 200mg each time with minimum 48hours apart. Each ml contains 20mg of elemental iron.

The response to a uniform dose over a range of pretreatment hemoglobin was studied.

- Hemoglobin estimation of intravenous blood

- Blood indices like MCV, MCH, MCHC, Haematocrit (PCV) estimation.

\section{Statistical analysis}

The results were noted, tabulated, analysed and expressed as descriptive statistics. $Z$ test has been used to find the significance of rise in blood indices within the study groups before and after treatment with $95 \%$ confidence interval. The results were analysed by using SPSS V-21 software.

\section{RESULTS}

The study was conducted in Department of Obstetrics and Gynaecology, GMERS Medical College, Gotri, Vadodara, Gujarat. The aim of the study was to see the 
effect of intravenous iron sucrose and oral ferrous sulphate in terms of safety, efficacy and compliance for the treatment of iron deficiency anaemia (moderate anaemia) in antenatal women aged 20-35 years with gestational age around 20-32 weeks.

The results were compared as rise in Blood indices, before and after taking IV Sucrose. Then finally the mean rise in Blood indices like $\mathrm{Hb}, \mathrm{MCV}$ and Hematocrit (PCV) were compared from baseline. The adverse effect profile of Intravenous iron sucrose was found to be less.

Table 1: Demographic data.

\begin{tabular}{|lllll|}
\hline Parameter & Minimum & Maximum & Mean & SD \\
\hline Weight & 40 & 75 & 52.06 & 5.60 \\
\hline Age & 20 & 35 & 26.25 & 2.05 \\
\hline $\begin{array}{l}\text { Gestational } \\
\text { age }\end{array}$ & 20 & 32 & 28.32 & 1.8 \\
\hline
\end{tabular}

Demographic data was tabulated and shown in Table 1. In present study, the range of weight was $40-75 \mathrm{~kg}$. Mean weight was $52.06 \mathrm{~kg}$ with SD of 5.60 . The age of the patients was between 20 and 35 years. Mean age was 26.25 years with SD was 2.05. We have taken patients with gestational age of 20-32 weeks. Mean gestational age was 28.32 and SD was 1.8 (Table 1). Distribution of gravidity in the study group was shown in Table 2 . In present study, total 70 patients $(35 \%)$ were primigravidas, $65(32.5 \%)$ were $2^{\text {nd }}$ gravidas and $65(32.5 \%)$ were 3 rd or more gravidas (Table 2).

Table 2: Distribution of gravidity in both groups.

\begin{tabular}{|lll|}
\hline Gravida & Number & Percentage \\
\hline PRIMI & 70 & 35 \\
\hline G-2 & 65 & 32.5 \\
\hline G-3 and more & 65 & 32.5 \\
\hline Total & $\mathbf{2 0 0}$ & $\mathbf{1 0 0}$ \\
\hline
\end{tabular}

Table 3: Distribution and comparison of MCV before and after treatment.

\begin{tabular}{|c|c|c|c|c|c|c|c|}
\hline Group & At & Minimum & Maximum & Mean & SD & $\mathrm{Z}$ value & P value \\
\hline \multirow{2}{*}{ IV iron sucrose } & Before & 55 & 78 & 69.7 & 5.74 & \multirow{2}{*}{-11.82} & \multirow{4}{*}{$\begin{array}{l}<0.05 \\
\mathrm{HS}\end{array}$} \\
\hline & After & 70 & 85 & 77.8 & 3.88 & & \\
\hline \multirow{2}{*}{ Oral ferrous sulphate } & Before & 57 & 75 & 65 & 4.8 & \multirow{2}{*}{-15.51} & \\
\hline & After & 72 & 85 & 74 & 5.0 & & \\
\hline
\end{tabular}

Table 4: Distribution and comparison of mean haemoglobin before and after treatment.

\begin{tabular}{|c|c|c|c|c|c|c|c|}
\hline Group & At & Minimum & Maximum & Mean & SD & $\mathrm{Z}$ value & P value \\
\hline \multirow{2}{*}{ IV iron sucrose } & Before & 7 & 9 & 7.9 & 0.35 & \multirow{2}{*}{-54.56} & \multirow{4}{*}{$\begin{array}{l}<0.05 \\
\mathrm{HS}\end{array}$} \\
\hline & After & 10.2 & 12 & 10.8 & 0.40 & & \\
\hline \multirow{2}{*}{ Oral ferrous sulphate } & Before & 7 & 9 & 7.8 & 0.30 & \multirow{2}{*}{-70.58} & \\
\hline & After & 9.8 & 10.6 & 10.2 & 0.16 & & \\
\hline
\end{tabular}

Table 5: Distribution and comparison of mean PCV (haematocrit) before and after treatment.

\begin{tabular}{|c|c|c|c|c|c|c|c|}
\hline Group & At & Minimum & Maximum & Mean & SD & $\mathrm{Z}$ value & P value \\
\hline \multirow{2}{*}{ IV iron sucrose } & Before & 24 & 34 & 28.36 & 2.2 & \multirow{2}{*}{-19.65} & \multirow{4}{*}{$\begin{array}{l}<0.05 \\
\mathrm{HS}\end{array}$} \\
\hline & After & 32 & 39 & 34.06 & 1.9 & & \\
\hline \multirow{2}{*}{ Oral ferrous sulphate } & Before & 25 & 35 & 29.6 & 2.1 & \multirow{2}{*}{-15.9} & \\
\hline & After & 30 & 38 & 33.8 & 1.6 & & \\
\hline
\end{tabular}

The range of MCV before treatment was 55-78 $\mathrm{fl}$ in case of IV iron and after treatment 70-85 fl. Mean MCV was $69.7 \mathrm{fl}$ (SD - 5.74) before IV iron sucrose which increases to $77.8 \mathrm{fl}(\mathrm{SD}-3.88)$ after treatment. In case of oral iron, the range was $57-75 \mathrm{fl}$ mean $\mathrm{MCV}$ was $65 \mathrm{fl}$ (SD - 4.8) which increases to $74 \mathrm{fl}$ (SD - 5.0). The rise in MCV was $8.1 \%$ and $9 \%$ in case of IV and oral iron respectively. This is statistically significant in both the groups (Table $3)$.

The range of $\mathrm{Hb}$ before treatment was $7-9 \mathrm{~g} \%$ in both the groups. The range of $\mathrm{Hb}$ after treatment of IV iron was
$10.2-12 \mathrm{~g} \%$. In case of oral iron, the range after treatment was $9.8-10.6 \mathrm{~g} \%$. Mean hemoglobin was $7.9 \mathrm{~g} \%$ before treatment and $10.8 \mathrm{~g} \%$ after treatment in case of IV iron and mean hemoglobin was $7.8 \mathrm{~g} \%$ before treatment and $10.2 \mathrm{~g} \%$ after treatment in case of oral iron and therefore a rise by $2.9 \%$ and $2.4 \%$ in 6 weeks respectively. This increase is significant (HS) (Table 4).

The range of PCV before IV iron was $24-34 \%$ and before oral iron was $25-35 \%$. The range of PCV after IV iron was $32-39 \%$ and after oral iron was $30-38 \%$. Mean PCV was $28.36 \%$ before treatment and raised to $34.06 \%$ after 
treatment in case of IV iron. Mean PCV was $29.6 \%$ before treatment and raised to $33.8 \%$ after treatment in case of oral iron. The rise in PCV was $5.7 \%$ and $4.2 \%$ in case of IV and oral iron respectively. This rise is highly significant (Table 5).

Adverse effects were $10 \%$ in the study groups. Gastrointestinal side effects like nausea, vomiting, dyspepsia, constipation, diarrhoea occurred predominantly in oral group. Thrombophlebitis, pain at the site of injection, fever was the adverse effects seen with iron sucrose injections. Though adverse effects were less with IV iron sucrose it was not statistically significant $(\mathrm{P}=0.09)$ (Table 6).

Table 6: Side effects profile of two groups.

\begin{tabular}{|lll|}
\hline Side effect & $\begin{array}{l}\text { No. of patients } \\
\text { Sucron }\end{array}$ & $\begin{array}{l}\text { Oral ferrous } \\
\text { sulphate }\end{array}$ \\
\hline Local pain & 5 & 0 \\
\hline Fever-malaise & 2 & 0 \\
\hline Dyspepsia & 0 & 3 \\
\hline Constipation & 1 & 3 \\
\hline Diarrhea & 0 & 1 \\
\hline Nausea/vomiting & 2 & 3 \\
\hline Total & $\mathbf{1 0}$ & $\mathbf{1 0}$ \\
\hline
\end{tabular}

\section{DISCUSSION}

Anemia due to Iron deficiency is the commonest malnutrition disorder seen throughout the world and in India, affecting $35-75 \%$ (average $56 \%$ ) of pregnant women in developing countries and $18 \%$ of women from industrialized countries are anemic. ${ }^{2}$ Currently, there are many oral iron and intravenous preparations available. The traditional treatments, i.e., oral iron therapy and blood transfusion, involve significant drawbacks. High doses of oral iron frequently cause side effects, and noncompliance is common. Administration of oral iron supplementations is not sufficient enough in order to reverse anemia promptly, due to the limited absorption, the gastrointestinal symptoms and the poor compliance for long treatment of the patients. As far as blood transfusions are concerned, because of the risk of infection (bacterial, viral, prions) and immunomodulation associated with allergenic blood products, especially in this young and otherwise healthy population, transfusions are used only in the most severe cases and particularly in life-threatening situations. Therefore, intravenous iron, has been considered as an alternative in the management of iron deficiency anemia.

A total of 200 antenatal women were selected and recruited in the study. Majority of women were in the age group of 22-25 years. Mean age of the patients in other studies were approximately similar to present study. The characteristics of patients in group A and in group B were statistically comparable in relation to age. In the study majority of women were in the age group of $22-25$ years. Mean age of the patients in other studies were approximately similar to present study. In all the studies maximum number of patients were primigravidas. This is explained by high prevalence of iron deficiency anemia in adult non-pregnant women (In present study group $46 \%$ and $38 \%$ were primigravidas). When these anemic women become pregnant, their anemia will be aggravated by increased need of iron during pregnancy, and it is important to screen iron deficiency anemia in all nonpregnant child bearing age group women as recommended by Centre of Disease Control and Prevention (CDC). In the present study the mean gestational age at the time of inclusion in the study group is comparable (28.5) to the mean gestational age in the study by Aggarwal Rohina $\mathrm{S}$ et al where it was 28.2 weeks. ${ }^{18}$

In this study, the mean baseline haemoglobin were $7.9 \mathrm{~g} / \mathrm{dl}(\mathrm{IV}$ iron) and $7.8 \mathrm{~g} / \mathrm{dl}$ (oral iron). Whereas, Post treatment haemoglobin after 8 weeks showed a mean value of $10.8 \mathrm{gm} / \mathrm{dl}$ (IV iron) and $10.2 \mathrm{~g} / \mathrm{dl}$ (oral iron) (p value $<0.05$ ), which is statistically significant. In the present study, the average rise of haemoglobin is $2.9 \mathrm{~g} / \mathrm{dl}$ and $2.5 \mathrm{~g} / \mathrm{dl}$ respectively ( $\mathrm{P}$ Value $<0.05)$. Therefore the overall increase in haemoglobin is good with IV iron. This is similar to the study by Aggarwal RS et al, where the average rise of haemoglobin was $5.03 \mathrm{~g} / \mathrm{dl}$ in intravenous group. ${ }^{18}$ In the study of Kharde PS et al, baseline haemoglobin was $7.6 \mathrm{~g} / \mathrm{dl}$ and $7.5 \mathrm{~g} / \mathrm{dl}$ in oral and IV groups respectively. The average rise of haemoglobin was $3.54 \mathrm{~g} / \mathrm{dl}$ and $5.3 \mathrm{~g} / \mathrm{dl}$ in oral and IV group respectively. ${ }^{19}$ In another study done by Momen AI et al in 1996, has shown baseline $\mathrm{Hb} 7.58$ and $7.66 \mathrm{~g} \%$ and MCV 68.6 and $70.8 \mathrm{fl} /$ cell in IV and oral group respectively. After 4 weeks $\mathrm{Hb} \%$ increased to 12.8 and $11.1 \mathrm{~g} \%$ and MCV increased to 82.6 and 74.9fl in IV and oral group respectively. In both studies, no major side effects were seen. ${ }^{20}$

With all these studies, it was evident that the rise in haemoglobin level is effective with Intravenous iron Sucrose. This can be explained by the fact that absorption of iron is better when given intravenously. The mean base line haematocrit (PCV) is $28.36 \%$ and $29.6 \%$ respectively and after treatment mean PCV was improved to $34.06 \%$ and $33.8 \%$ ( $P$ value $<0.01$ ). An average rise of $5.7 \%$ and $4.2 \%$ respectively was observed in the study group. This is statistically significant.

There were minimal side effects in the study group. Only $10 \%$ of women had minimal side effects like pain at the injection site, mild thrombophlebitis with IV iron sucrose and predominantly gastrointestinal side effects with oral iron. $\mathrm{P}$ value $=0.09$ indicate that these adverse effects were not significant. Similar observations were reported in other studies like Kharde PS et al, Bayoumeu F et al and Raja KS et al without serious adverse effects. ${ }^{19,21,22}$ 


\section{CONCLUSION}

The present study showed that treatment of anaemia with intravenous iron sucrose and oral iron would increase the haemoglobin considerably. This study proved that iron sucrose when given intravenously there was a rapid improvement in anaemia. IV iron sucrose was proved to be safe with minimal side effects. A superior tolerability profile and a better efficacy profile, strongly suggest that it can be considered as an alternative drug for treatment of moderate anaemia in antenatal women to blood transfusion.

\section{ACKNOWLEDGMENTS}

Authors would like to acknowledge the support of the Professor and HOD of OBG, the colleagues in Obstetrics and Gynaecology Department who helped in completion and success of the study.

Funding: No funding sources Conflict of interest: None declared

Ethical approval: Not required

\section{REFERENCES}

1. WHO/UNICEF/UNU. Iron deficiency anaemia: assessment, prevention, and control. Geneva, World Health Organization, (WHO/NHD/01.3); 2001. Available at; http://www.who.int/nut/documents/ida assessment_prevention_control.pdf, Accessed on 27 July 2004.

2. World Health Organization. Maternal Health and Safe Motherhood Programme and World Health Organization. Nutrition Programme. The prevalence of anaemia in women: a tabulation of available information, $2^{\text {nd }}$ ed. World Health Organization; 1992. Available at; http://www.who.int/iris/ handle/10665/58994. Accessed on 16 June 2012.

3. Luwang NC, Gupta VM, Khanna S. Anaemia in pregnancy in a rural community of Varanasi. Ind J Prev Soc Med. 1980;11:83-8.

4. Agrawal V, Tejwani S. Prevalence of iron deficiency anaemia in Indian antenatal women especially in rural 98 areas. Ind Med Gaz Sept. 1999;300-3.

5. Noronha JA, Bhaduri A, Bhat VH. Prevalence of anemia among pregnant women: A community-based study in Udupi (D.t), Health and Population Perspectives and Issues. 2008;31(1):31-40.

6. Haider BA, Olofin I, Wang M, Spiegelman D, Ezzati M, Fawzi WW. Anaemia, prenatal iron use, and risk of adverse pregnancy outcomes: systematic review and Meta-analysis. BMJ. 2013;346:f3443.

7. Ivan EA, Mangaiarkkarasi A. Evaluation of anaemia in booked antenatal mothers during the last trimester. J Clin Diagnost. 2013;7(11):2487-90.
8. Jiji DB, Rajagopal K. A study to assess the pregnant women the knowledge and risk factors of anaemia among the pregnant women selected and attending Healthcare facilities in Sebha, Libya. J Sci. 2014;4(1):19-22.

9. Patra S, Pasrija S, Trivedi SS, Puri M. Maternal and perinatal outcome in patients with severe anaemia in pregnancy. Int J Gynaecol Obstet. 2005;91:164-5.

10. Kalaivani K. Prevalence and consequences of anaemia in pregnancy. Indian J Med Res. 2009;130(5):627-33.

11. Scholl TO. Iron status during pregnancy: setting the stage for mother and infant. Am $\mathbf{J}$ Clin Nutr. 2005;81:1218S-22S.

12. Lozoff B, Jimenez E, Hagen J, Mollen E, Wolf AW. Poorer behavioral and developmental outcome more than 10 years after treatment for iron deficiency in infancy. Pediatrics. 2000;105:e51.

13. Komolafe JO, Kuti O, Ijadunola KT, Ogunniyi SO. A comparative study between intramuscular iron dextran and oral ferrous sulphate in the treatment of iron deficiency anaemia in pregnancy. J Obstet Gynaecol. 2003;23(6):628-31.

14. Scot BS, George MR. Parental iron therapy option. Am J. 2004;76:74-8.

15. Chandler G, Harchowal J, Macdougall IC. Intravenous iron sucrose: establishing a safe dose. Am J Kidn Dis. 2001;38:988-91.

16. Dutta DC. Medical illness complicating pregnancy, Textbook of Obstetrics, 6th Edition. (Ed Konar H) The central Book Agency Pvt Ltd. Culcutta; 2004:262-271.

17. Dewan B, Philipose N, Balasubramanian A. Assessment of intravenous Iron Sucrose in the management of anemia in gynecological and obstetrical practice. Obstet Gynaecol India. 2012;62(3):281-5.

18. Aggarwal RS, Mishra VV, Panchal NA, Patel NH, Deshchougule VV, Jasani AF. Evaluation of iron sucrose and oral iron in the management of iron deficiency anemia in pregnancy. NJCM. 2012;93:415-6.

19. Kharde PS, Bangal VB, Panicker KK. Comparative study of intravenous iron sucrose versus oral iron therapy in postpartum period. IJBAR. 2012;89:102- 08 .

20. Momen AI, Meshariet AK. Intravenous Iron sucrose complex in the treatment of iron deficiency anemia during pregnancy. Eur J Obstet Gynecol Reprod Biol. 1996;69:121.

21. Bayoumeu F. Iron therapy in iron deficiency anaemia in pregnancy, intravenous route versus oral route. AM J Obstet Gynecol. 2002;186:518-212.

22. Raja KS. Intravenous iron sucrose complex in iron deficiency anaemia in pregnancy. RWJ. 2003;216:64-9.

Cite this article as: Prajapati SM, Patel MK. A study of efficacy of oral iron and intravenous iron sucrose in the treatment of moderate anemia in pregnancy. Int J Reprod Contracept Obstet Gynecol 2019;8:2221-5. 